The piles in the tests described in the Paper were driven open-ended and the material inside was cleaned out frequently. This was considered to be a non-displacement pile (p. 182). It might be argued that because the level of the soil dropped inside the pile during driving some plug action was occurring and some compaction of the surrounding soil took place. The important point is 'how much?' What does one assume in design? After many tests it would be possible to obtain a factor to apply to the Meyerhof formula to allow for the effect of the method of installation of the piles, which method would have to be carefully controlled. In the absence of such a figure to assume no compaction is playing safe.

The Authors would welcome other opinions on this point.

\title{
REFERENCES
}

Meyerhof, G. G. (1956). Penetration tests and bearing capacity of cohesionless soils. J. Soil Mech. Fdns Div. Am. Soc. civ. Engrs 82, SM1, January, 19 pp.

MeyerhoF, G. G. (1971). Private communication.

THorburn, S. (1971). Private communication.

\section{SHEAR STRENGTH OF MONTMORILLONITE}

(Mesri, G. \& Olson, R. E. (1970). Géotechnique 20, No. 3, 261-270)

\section{A. Sridharan and S. Narasimha Rao, Civil and Hydraulics Engineering Department, Indian Institute of Science}

The Authors have presented interesting data with regard to the shear strength of montmorillonite. It is interesting that the same failure envelopes were obtained by the Authors for undrained and drained tests. The experience of the Writers on similar types of calcium and sodium montmorillonite show a significant difference between the undrained and drained failure envelopes. Table 1 shows their index properties. Fig. 1 shows the failure envelopes for calcium montmorillonitc and Fig. 2 shows those for sodium montmorillonite.

The Writers have applied Bishop's (1954) energy correction to account for the work expended in the volume change during shearing. The difference between undrained and drained

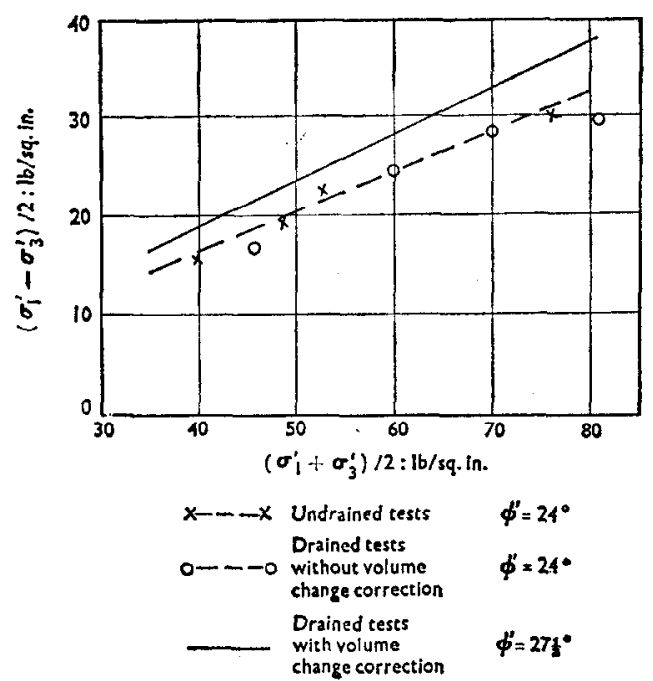

Fig. 1. Effective stress failure diagram for calcium montmorillonite

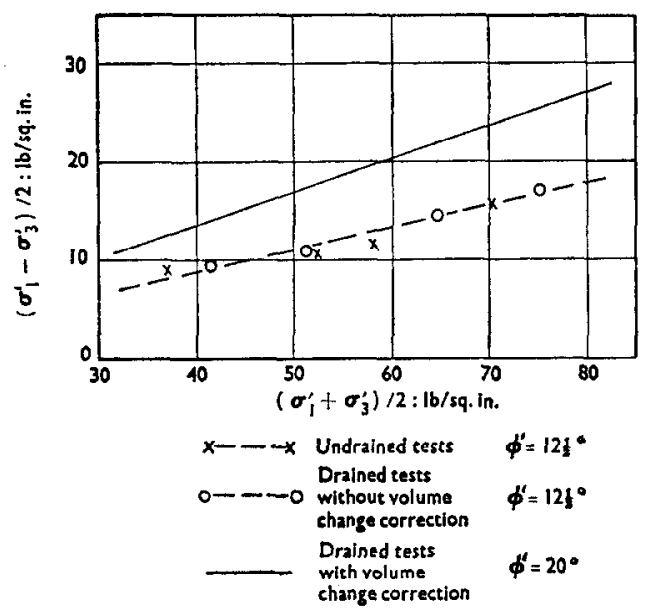

Fig. 2. Effective stress failure diagram for sodium montmorillonite 
Table 1

\begin{tabular}{l|c|c}
\hline & Calcium montmorillonite & Sodium montmorillonite \\
\hline Liquid limit & $222 \%$ & $686 \%$ \\
Plastic limit & $88 \%$ & - \\
\hline
\end{tabular}

(with volume change correction) envelopes is significant, especially for sodium montmorillonite. The Writers have obtained essentially the same envelope for undrained and drained tests without any volume change correction. It would be interesting to know the method applied by the Authors to the volume change corrections.

The results obtained using electrolyte of different concentrations have also been presented by the Authors. The Writers question whether or not the concentration would be changed during consolidation. Perhaps circulation of the pore fluid with required concentration after the end of consolidation might ensure the desired electrolytic concentration.

\section{REFERENCE}

Bishop, A. W. (1954). Correspondence on Shear characteristics of a saturated silt, measured in triaxial compression. Géotechnique 4, No. 1, 43-45.

\section{ANISOTROPIC ELASTIC PARAMETERS FOR SOIL \\ (PICKering, D. J. (1970). Géotechnique 20, No. 3, 271-276)}

\section{R. N. Chowdhury and G. J.W. King, University of Liverpool}

The Author has referred only to the work of Lempriere (1968) in connexion with the bounding values of the Poisson's ratios. Hearmon (1961) considering precisely the approach used in the Paper stated, 'The fact that the strain energy is positive imposes restrictions on the values of the elastic constants (Voigt, 1910, § 278; Nye, 1957, ch. viii, §4.1; Alers and Neighbours, 1957)'. He continued that this implies that all diagonal elements are positive and in the hexagonal system, for instance, the remaining conditions reduce to

$$
\left.\begin{array}{rl}
c_{11}^{2} & >c_{12}^{2} \\
c_{33}\left(c_{11}+c_{12}\right) & >2 c_{13}^{2} \\
c_{11} c_{33} & >c_{13}^{2}
\end{array}\right\} \quad \cdot \quad \cdot \quad \cdot \quad \cdot \quad \cdot .
$$

Most of the bounding values on the elastic constants are thus obtained directly by considering the diagonal elements of equation (2) of the Paper to be positive. The remaining conditions mentioned by Hearmon (1961) give the rest of the restrictions with suitable change of notation (see also Barden, 1963; Dooley, 1964). However, the representation of the bounding values of the parameters in 'three-dimensional space' is of interest.

With regard to a saturated soil deforming under conditions of no drainage, there is an important difference between the elastic parameters of the soil-water system and those of the soil skeleton. It would be more appropriate to refer to these parameters as total and effective stress parameters respectively. The use of the same notation for the elastic parameters in equations (1)-(8) on the one hand and equations (9)-(12) on the other is, therefore, misleading. Further, the same bounding values do not apply to the effective stress parameters since the strain energy of the soil-water system must be positive. Indicating the matrix of effective stress parameters by $[\bar{C}]$ the strain energy may be expressed in the form of $\frac{1}{2}\{\bar{\sigma}\}^{T}[\bar{C}]\{\sigma\}$ where $\{\bar{\sigma}\}$ is the matrix of effective stresses. This expression is markedly different from that in terms of the total stress elastic parameters. 